\title{
Gestão municipal: transparência dos portais eletrônicos como promotores do accountability
}

\section{Municipal management: transparency of electronic portals as promoters of accountability}

\author{
Vania Luiza Luiza Pagliari ${ }^{1}$, Nilton Cesar Lima ${ }^{2}$, Christian Luiz da Silva ${ }^{3}$ \\ ${ }^{1}$ Universidade Federal de Uberlândia - UFU, , Uberlândia, MG, Brasil. ORCID: http://orcid.org/0000-0003-4735-7982 \\ 2 Universidade Federal de Uberlândia - UFU, , Uberlândia, MG, Brasil. ORCID: http://orcid.org/0000-0002-8933-9953 \\ ${ }^{3}$ Universidade Federal Tecnológica do Paraná - UTFPR, Curitiba, PR, Brasil. ORCID: http://orcid.org/0000-0002-4074-5184
}

Autor para correspondência/Mail to: Vania Luiza Luiza Pagliari, vaniapagliari@unirv.edu.br

Recebido/Submitted: 24 de abril de 2020; Aceito/Approved: 24 de maio de 2020

Copyright (c) 2020 Pagliari, Lima \& Silva. Todo o conteúdo da Revista (incluindo-se instruções, política editorial e modelos) está sob uma licença Creative Commons Atribuição-NãoComercial-Compartilhalgual 3.0 Não Adaptada. Ao serem publicados por esta Revista, os artigos são de livre uso em ambientes educacionais, de pesquisa e não comerciais, com atribuição de autoria obrigatória. Mais informações em http://revistas.ufpr.br/atoz/about/submissions\#tcopyrightNotice.

\begin{abstract}
Resumo
Introdução: Aborda a transparência dos portais eletrônicos como promotores do accountability na gestão municipal. Objetiva identificar quais indicadores socioeconômicos estão relacionados ao nível de transparência nos municípios. Metodologia: Sob uma abordagem quantitativa, utiliza uma amostra não intencional e probabilística de 360 municípios. Por meio da técnica de regressão linear múltipla, verifica quais variáveis estariam relacionadas à transparência pública. Resultados: Admite para aplicação da técnica de regressão linear as variáveis explicativas: receita total, RCL, ativo, população, população alfabetizada, IDH-M, PIB per capitae renda per capita. Na observação dos portais eletrônicos, a média de transparência foi de 3,76. Conclusão: O modelo de regressão explica 11,9\% da variação no índice de transparência. Responde ao problema de pesquisa, aceitando a hipótese geral e verificando que todas as variáveis explicativas estão relacionadas ao índice de transparência.

Palavras-chave: Contabilidade pública; Transparência pública; accountability
\end{abstract}

\begin{abstract}
Introduction: It presents the transparency of electronic portals as promoters of accountability in municipal management. The objective of the study is to identify which socioeconomic indicators are related to the level of transparency in the municipalities. Method: Under a quantitative approach, it uses an unintended and probabilistic sample of 360 municipalities. Using the multiple linear regression technique, it verifies which variables are related to public transparency. Results: It considers to the application of the linear regression technique the explanatory variables: total income, RCL, assets, population, literate population, HDI-M, per capitaGDP, and per capitaincome. The mean transparency was 3.76. Conclusion: The regression model explains $11.9 \%$ of the variation in transparency index. It responds to the research problem and accepts the general hypothesis and verifies that all the explanatory variables are related to the transparency index.
\end{abstract}

Keywords: Public accounting; Public transparency; accountability

\section{INTRODUÇÃO}

No setor governamental, as Tecnologias de Informação e Comunicação (TIC) têm sido utilizadas tanto em atividades internas quanto no relacionamento com a comunidade externa: cidadãos, fornecedores, sociedade e outros. Um sinal dessa crescente informatização tem sido a utilização de portais eletrônicos como ferramentas de relacionamento com a população: de um lado, apresentam a identidade do governo (disponibilizando serviços e informações) e, de outro, podem ser capazes de acolher as necessidades da população (Pinho, 2008). A utilidade dos portais eletrônicos vai muito além, podendo, inclusive, promover a transparência e accountability. Lock (2003) acrescenta ainda que a transparência aumenta a credibilidade do governo e favorece o controle social.

Para facilitar a promoção da transparência, em 2012, entrou em vigor no país a Lei $\mathrm{n}^{\circ}$ 12.527/2011 de Acesso à Informação (LAI). Com o intuito de regulamentar o direito de acesso às informações públicas, foram criados mecanismos que possibilitam a obtenção de informações de qualquer ente público, independentemente da esfera ou poder a que pertença.

Uma das dificuldades da implantação total da LAI nos municípios é a falta de dispositivos legais que regulamentem o acesso à informação previsto. Os municípios que ainda não sancionaram leis para regulamentar o acesso à informação sujeitam-se, portanto, aos dispositivos gerais presentes na LAI, dificultando, mas não impedindo, o acesso à informação por qualquer interessado.

Para avaliação dos portais da transparência de entes públicos, Birderman e Puttomatti (2015) propõem indicadores capazes de determinar o nível de transparência das informações divulgados pelos estados e capitais brasileiras. A metodologia proposta ficou conhecida como Índice de Transparência (IT), avaliando inicialmente os portais dos executivos estaduais e federal. Iniciado em 2011, o projeto foi reconhecido em 2012 pela Organização das 
Nações Unidas (ONU) como um importante mecanismo para aprimorar a transparência das contas públicas (ONU, 2012).

Nota-se que, por tratar-se de um objeto de estudo que busca investigar a transparência de informações nos municípios, logo, a presente pesquisa também remete a similaridades com o eixo de investigações encontrados na Ciência da Informação.

Como os municípios representam a esfera governamental mais próxima dos cidadãos, supõe-se que o impacto da promoção da transparência e accountabilitypor parte dos entes municipais seja mais significativo para a promoção da cidadania e democracia do que nos entes estaduais e federal. Entretanto, os municípios são os que mais enfrentam dificuldades para implantação da accountability em virtude da escassez de recursos humanos, financeiros e tecnológicos (Akatsu \& Pinho, 2002).

Estudos sobre a promoção da transparência apontam alguns indicadores que possuem relação com o aumento do nível de evidenciação contábil, como: desenvolvimento econômico; receita orçamentária; despesa total; resultado primário; taxa de alfabetização; IDH-M (Índice de Desenvolvimento Humano Municipal) e Índice de Qualidade dos Municípios (Santana Junior, 2008; Cruz, Silva, e Santos, 2009; Souza, Boina, e Avelar., 2013). Entretanto, os estudos alertaram sobre possibilidades de existência de alguns limitadores, pois não houve investigações empíricas de relevância quantitativa, uma vez que, nos apontamentos pesquisados, a seleção da amostra foi intencional, e não probabilística, diminuindo a confiabilidade da amostra e dos resultados das pesquisas, impossibilitando a generalização dos resultados (Souza et al., 2013).

Entende-se que os limitadores impedem a generalização por resultados inclusive em épocas de eleição. Nesse caso, tem-se que a Teoria das Escolhas Públicas (TEP) justifique a necessidade por resultados mais robustos decorrente de uma maior transparência dos atos públicos, capaz de corresponder à maximização de votos e motivar governantes durante o processo de tomada de decisão em detrimento do bem-estar da coletividade (Viana, 2010). Como, por exemplo, ao supor que indicadores socioeconômicos estejam relacionados à promoção da transparência e consequente accountability, logo, espera-se que a transparência tende a diminuir o número de eleitores menos informados e a aumentar a accountability. Assim, o gestor defronta-se com o dilema: se diminuir a transparência, incorrerá na maximização dos efeitos da TEP, aumentando o número de eleitores pouco informados e desfavorecendo o bem-estar social.

Diante do contexto e sob a ausência de um panorama nacional quanto à promoção da transparência dos municípios brasileiros, surge o seguinte problema norteador desta pesquisa: quais indicadores socioeconômicos estão relacionados ao nível de transparência nos municípios brasileiros? A partir dessa problematização, tem-se como objetivo identificar indicadores socioeconômicos relacionados ao nível de transparência nos municípios brasileiros. Admitindo-se, portanto, como hipótese "a relação entre os indicadores socioeconômicos e o nível de transparência nos municípios brasileiros".

Esta pesquisa justifica-se, até o momento, pela quantidade incipiente de estudos que apresentem o panorama nacional da transparência dos municípios brasileiros. Atualmente, há estudos que analisam a transparência de alguns municípios relacionados a um estado específico (Akatsu e Pinho, 2002; Lock, 2003; Santana Junior, 2008; Cruz et al., 2009; Souza et al., 2013). Entretanto, não há uma metodologia padronizada ou seleção da amostra não intencional e probabilística que permita a generalização dos resultados. Este artigo torna-se relevante ao demonstrar quais indicadores estão associados ao nível de transparência, podendo servir de norteador para a implantação de políticas públicas que diminuam os efeitos da TEP, tornando os cidadãos agentes ativos nas conduções das políticas públicas.

\section{TRANSPARÊNCIA, ACCOUNTABILITY E RESPONSABILIDADE FISCAL}

A preocupação com a transparência na gestão pública ocorreu de modo mais intenso nos anos 1990 por integrar as agendas governamentais. Transparência é algo oposto à privacidade e confidencialidade, ou seja, a abertura da estrutura do governo e de suas funções ao público em geral, permitindo que o público e os mercados conheçam a posição financeira do mercado, os custos e os benefícios de cada atividade estatal e as implicações econômicas e sociais de cada ação governamental (Heald, 2003).

A transparência só é efetiva quando é capaz de garantir que as informações sejam íntegras, produzidas num ambiente com um controle razoável dos processos desenvolvidos e auditadas por órgãos independentes, que exercem o papel de controle externo (Cruz, 2010).

Uma vantagem apontada para a promoção da transparência está no aumento da confiança que a população deposita no governo. Isso porque uma gestão transparente permite que o mercado acompanhe e compare as operações previstas e realizadas pelo governo (Kopits \& Craig, 1998). Tem-se observado, tanto no setor público quanto privado, um aumento na demanda por prestação de contas e transparência, assim como uma crescente cobrança pelo estabelecimento de controles, buscando o equilíbrio das instituições (Cruz, 2010). Os mecanismos de controle e prestação de contas ensejam custos, uma das desvantagens da promoção da transparência. Outra 
desvantagem que deve ser considerada é o risco do comportamento hostil de determinados grupos frente a alterações nas propostas governamentais (Kopits \& Craig, 1998). Embora haja algumas desvantagens em sua promoção, os autores advertem, também, que práticas sem transparência tendem a desestabilizar a economia, gerando distorções e agravando desigualdades.

Embora benéfica, Gomes Filho (2005) admite que a promoção da transparência não parece ser uma tarefa fácil. Aproveitando as TIC disponibilizadas em larga escala, o governo tem utilizado dessas ferramentas para ampliar a participação popular: o chamado e-government, que "visa reforçar a transparência e a prestação de contas dos governos e promover alterações no papel passivo de boa parcela da sociedade, dando a ela um mecanismo de amplo alcance e que possibilita a participação social" (Souza et al., 2013, p. 02). No caso brasileiro, entretanto, a utilização das TIC para promoção da transparência ainda não está plenamente consolidada.

Entretanto, há esforços sendo implementados a partir de maio de 2019, por meio da Organização Internacional de Normalização (ISO), com a constituição da norma ISO 37122, responsável pelos indicadores para serviços municipais e qualidade de vida nas comunidades, que reconhece e classifica o progresso de uma cidade como: "cidade inteligente" (ISO, 2012).

Por outro lado, ao observar mecanismos de transparência de gestão pública em outros países, cuja mensuração, análise e divulgação de informações sobre o desempenho financeiro e não financeiro do governo australiano, por serem um meio comumente utilizado e representar um modo para a prestação pública de contas, constatou-se que: neste, os indicadores financeiros, de eficiência/efetividade, qualidade dos serviços sociais e de performance governamental, encontram-se com várias inadequações nos relatórios tanto financeiros quanto não financeiros, entre os anos de 1998 a 2002. Ou seja, nem mesmo foi possível monitorar as ações governamentais no governo australiano, pois os próprios relatórios estavam deficientes. Contudo, o estudo destacou a necessidade da adequação e melhoria dos relatórios para aumentar a responsabilização pública (Lee, 2006).

Outros estudos também constataram essa anomalia nos relatórios australianos, conforme abordado por Carlin e Guthrie (2001), cuja verificação da divulgação de indicadores não financeiros nos relatórios australianos entre os anos de 1999 e 2001, embora tenha revelado um aumento em sua divulgação, na finalidade de cooperar com a transparência, os mesmos encontravam-se comprometidos por falhas nas informações e, portanto, fragilizando a confiança dos indicadores apresentados. Por outro lado, num estudo realizado por Herawaty e Hoque (2007), ao investigar o comprometimento na divulgação dos relatórios do governo australiano, sem se ocupar da qualidade e padronização das informações divulgadas, os autores, revelaram que a divulgação de informações obrigatórias é superior à divulgação voluntária entre os anos de 2005 e 2006. Outro apontamento encontrado foi que, se o gestor público é fiscalizado, a divulgação é maior.

Alguns pesquisadores brasileiros têm concentrado esforços para desenvolver uma metodologia capaz de comparar os diferentes entes públicos. Sugeriu-se uma série de indicadores que poderiam apresentar o nível de transparência pública, entretanto, o modelo não foi testado para garantir a eficácia dos resultados (Carlos et al., 2008). Outros estudos preconizaram as exigências da Lei de Responsabilidade Fiscal (LRF) como indicadores de transparência, sem considerar a frequência ou a facilidade de se encontrar uma informação, o que enfraquece o conceito de transparência defendido por Santana Junior (2008).

Entretanto, há exemplos em outros países, como o modelo proposto por Cruz (2010), que é uma adaptação do Índice de Trasparencia de los Ayuntamientos, capaz de analisar a transparência dos municípios espanhóis. Concomitantemente, têm-se os modelos trazidos por Birderman e Puttomatti (2015), premiados pela ONU, cuja aplicação em 2011 em vários países revelou que o IT permite verificar o nível de transparência dos governos estaduais e federal bienalmente.

A partir dos resultados anteriormente mencionados, nota-se que a promoção da transparência é necessária e de grande relevância social, embora complexa, devido às características de cada país (Cruz, 2010). Trata-se de uma política específica, que deve ser implementada da forma correta e que exige capacidade da autoridade pública. O primeiro esforço brasileiro em promover transparência está na Constituição Federal (CF) de 1988. Está previsto em seu artigo $5^{\circ}$ como um direito fundamental o acesso à informação de seu interesse ou da coletividade (Brasil, 1988). Além do acesso à informação, em seu artigo $37^{\circ}$, é estabelecido que todos os órgãos da administração pública devem ser orientados por princípios de legalidade, impessoalidade, moralidade, publicidade e eficiência (Brasil, 1988). Dar publicidade aos atos administrativos significa que o povo tem o direito de estar ciente dos atos realizados pelos administradores públicos, necessários para o exercício do controle social (Platt Neto, da Cruz, Ensslin, \& Ensslin, 2007).

Embora o conceito de publicidade esteja presente na CF, Campos (1990) afirma que, naquela época ainda não havia mecanismos eficientes para promover o controle social. Surge, então, um novo esforço para a promoção da transparência pública, através da promulgação da LRF (Platt Neto et al., 2007). A LRF estabelece normas para a promoção da transparência, controle e fiscalização da gestão pública. A transparência, na LRF, tem por finalidade facilitar o acesso às informações relacionadas à gestão pública, além de determinar os procedimentos necessários à promoção da transparência (Cruz, 2012). 
Deve-se atentar, portanto, que o princípio constitucional da publicidade não é igual ao conceito de transparência pregado na LRF. Isso porque o primeiro determina apenas a divulgação dos atos e, o segundo, que a divulgação seja compreensível aos cidadãos. Para que a transparência seja efetiva, portanto, não basta apenas divulgar. Em linhas gerais, as principais características de uma gestão transparente é o acesso a informações e possibilidade da participação popular na gestão. Salienta-se que a transparência só é efetiva quando realizada de forma compreensiva, clara, aberta e simples ao cidadão. Portanto, a manutenção da transparência é um desafio para a promoção de uma gestão fiscal e orçamentária responsável (Cruz, 2010).

No Brasil, a LRF estabelece as principais condições para o equilíbrio das contas públicas: ações planejadas e transparentes e mecanismos eficientes de controle (Cruz, 2012). A LRF está apoiada em quatro pilares: planejamento, controle, responsabilização e transparência (Sacramento \& Pinho, 2007). Os pilares planejamento e transparência compreendem a primeira condição para o equilíbrio das contas públicas (ações planejadas e transparentes). (Cruz, 2012) afirma que o propósito principal do planejamento é definir objetivos e gerar processos capazes de garantir a disponibilidade da estrutura e recursos necessários para a execução de determinada ação.

A exigência de disponibilização das informações financeiras e fiscais à população de maneira compulsória por parte dos gestores certamente produziu grandes avanços para a transparência pública. Entretanto, os esforços dos gestores devem ir além do preconizado na lei, uma vez que "os relatórios fiscais além de se restringirem às informações contábil-financeira, são de difícil compreensão pela população leiga" (Viana, 2010, p. 48). Os gestores públicos devem implementar políticas que visem a divulgação de metas, ações, programas, projetos e resultados de maneira acessível e compreensível (Viana, 2010).

O controle dos gastos públicos (terceiro pilar) é realizado pelos órgãos de contabilidade e auditoria dos entes federativos e pelo Poder Legislativo. Sob a existência de duas formas: controle externo e controle interno. O controle interno (ou primário) são órgãos dentro do próprio ente, responsáveis pelo cumprimento dos princípios que previstos na CF: legalidade, impessoalidade, moralidade, publicidade e eficiência. Já o controle externo é responsabilidade do Poder Legislativo (Sales \& Martins, 2014).

Fora da estrutura da administração pública, encontra-se o controle social, que é o acompanhamento e fiscalização constante dos atos públicos pela sociedade civil (Cruz, 2015). Este é o elemento para o pilar 'responsabilização', que obriga o gestor a prestar contas da utilização do dinheiro público à sociedade, possibilitando cobranças de medidas cabíveis quando as condições para o equilíbrio das contas públicas são desrespeitadas (Sales \& Martins, 2014).

Na pesquisa desenvolvida por Sales e Martins (2014), foram levantados alguns desafios que a LRF ainda não conseguiu superar: dificuldade em executar o orçamento conforme o previsto e distorções em relação ao controle financeiro. Deve-se atentar ao fato de que "alguns gestores, tantas vezes inescrupulosamente, agem de maneira a dificultar e encobrir eventuais distorções no que tange ao rigoroso controle disciplinado na LRF" (Sales \& Martins, 2014, p. 251).

Outro desafio que merece especial atenção é a falta de transparência. Tal dificuldade justifica-se pela ausência de condições técnicas para emissão dos relatórios fiscais: poucos municípios brasileiros possuem condições técnicas para produção de informação, além disso, há pouca orientação de instâncias superiores no sentido de estabelecer critérios unificados para promoção da transparência e aplicação de sanções em caso de descumprimento (Leite, 2011). Para que haja qualidade nos serviços públicos prestados à população, esta deve participar mais ativamente da Administração Pública (Sales \& Martins, 2014). Tal participação pode ser fortalecida com a utilização da internet na comunicação entre os envolvidos. É necessário que a própria população se conscientize de seu papel como agente de mudanças sociais, opinando sobre o rumo do país permanentemente, promovendo a accountability.

O termo accountability ainda é tema de muita discussão e controvérsia (Angélico, 2012). Observa-se que, ao longo do tempo, o entendimento sobre accountability remete à importância da efetiva participação popular e a responsabilização do gestor por suas ações.

No setor público, a accountability foi dividida em horizontal e vertical por O’Donnell (1998): a accountability horizontal refere-se à capacidade e poder dos órgãos do Estado de acompanhar a rotina das ações e omissões de outros órgãos e agentes do Estado. Trata-se do controle de um órgão sobre o outro, o que inclui o controle exercido, por exemplo, por ouvidorias e tribunais de contas. A accountability vertical, por sua vez, está voltada para as formas como a sociedade pode cobrar a prestação de contas, através de mecanismos institucionais, como as eleições (Mota, 2006). No decorrer deste estudo, a accountability será tratada como um processo (iniciado através da promoção da transparência) que permite o acompanhamento e participação popular na avaliação das ações governamentais. Mediante a avaliação das ações governamentais, o gestor será responsabilizado caso os recursos a ele confiados não sejam geridos a contento.

Ao relacionar a democracia com a accountability, pode-se tomar como exemplo o caso dos Estados Unidos (Campos, 1990). Nesse país, a cultura da accountability é muito mais desenvolvida que a brasileira (prova disso, é que nela nem há uma tradução para o termo). Na maioria dos países da América Latina, O’Donnell (1998) acredita que a accountability vertical é promovida (há participação popular nas eleições, com voto direto e 
razoavelmente livres e justas), enquanto a horizontal é fraca, pois os conceitos liberais e republicanos, nestes países, ainda são frágeis. Tal situação prejudica a promoção da accountability como um todo, uma vez que a vertical é promovida periodicamente e, a horizontal, devendo ser um exercício também frequente, tende a ser fraca ou nula.

O processo de promoção da accountability é determinado pelo relacionamento entre as duas partes: governo e cidadão (Campos, 1990). A autora afirma ainda que, enquanto o povo não se organizar, abandonando a posição de tutelado pelo Estado, não haverá promoção da accountability. É justamente essa organização da sociedade civil uma das causas da diferença entre o estágio de accountability promovido pelos governos americano e brasileiro, uma vez que a accountability é diretamente ligada ao desenvolvimento da democracia: quanto mais democrático, maior a accountability (Campos, 1990, p. 35-37).

Sabido que o exercício da accountability permite ao cidadão conhecer os atos praticados pelos gestores públicos, cabe destacar que a este existe a promoção de um debate entre os gestores eleitos e os cidadãos a ser exercido e cobrado pela sociedade (Sacramento \& Pinho, 2007).

Apesar da importância da accountability, há uma discrepância entre a disposição do governo em disponibilizar informações e aquilo que os cidadãos esperam. Esta assimetria informacional é verificada tanto no setor privado quanto público e ocorre porque os gestores podem agir por interesses próprios em detrimento do interesse da coletividade (Icerman \& Sinason, 1996 apud Cruz, 2010).

Por fim, nota-se que transparência e accountability são conceitos indissociáveis. A accountability só é possível a partir da abertura da gestão pública à população através da transparência, inerente à aceitação da crítica, na busca pela eficiência (Oliveira, 2007). Essa crítica realizada pela população só é possível através da accountability.

\section{TEORIA DAS ESCOLHAS PÚBLICAS (TEP)}

A TEP foi inicialmente formulada por James Buchanan e Gordon Tullock, quando publicaram o livro "The Calculus of Consent", em 1962 (Bernabel, 2009). Desde sua formulação, economistas têm se dedicado a analisar as motivações dos gestores públicos. É um ramo da economia que explica as interações institucionais dentro do setor público. Estudam-se as motivações dos governantes nas tomadas de decisões, visando maximizar o número de votos e aumentar a probabilidade de eleição (Viana, 2010).

Três fundamentos formam a base da TEP: o individualismo metodológico, o homo economicus como premissa do comportamento do indivíduo e a economia como ciência de trocas (Jiménez, 2008). O individualismo metodológico apregoa que as organizações são um conjunto de indivíduos, e estes são a unidade base das análises, já que possuem motivações, valores e preferências (Pereira, 1997). O segundo fundamento defende que os indivíduos são naturalmente egoístas, racionais e maximizadores (Jiménez, 2008). Costa, Freire, Gartner, e Clemente (2013) afirmam que a política é um mercado de trocas, que são realizadas para satisfação dos interesses pessoais dos indivíduos envolvidos (trocas são a base do problema econômico).

Os personagens da TEP podem ser agrupados em três grandes grupos (Jiménez, 2008):

- eleitores: elegem os políticos. São contribuintes e beneficiários dos serviços prestados

- políticos: eleitos como representantes dos eleitores, preparam e decidem as políticas públicas;

- burocratas: empregados do governo que controlam o funcionamento estatal.

Em boa parte do serviço público, governantes agem por motivações políticas, visando permanecer no cargo, ao invés de se preocupar com o "bem comum". Não raro, essas motivações influem nas decisões políticas (Viana, 2010). Como a promoção da transparência e consequente accountability podem influenciar na aprovação da gestão, torna-se importante estudar a TEP.

Até o momento, o foco principal dessa teoria tem sido a razão pela qual os gestores tendem a alocar recursos cujo valor social é questionável (Besley, 2011). A TEP analisa falhas de governo provocadas por questões como o horizonte temporal dos representantes eleitos, restrições orçamentárias, financiamento eleitoral (Samuelson \& Nordhaus, 2009). Em resumo, a TEP descreve como os governantes tomam as decisões sobre impostos, despesas e outras políticas públicas (Viana, 2010). Para compreender tal afirmação, é necessário voltar ao momento em que é atribuído poder de gestão ao agente público: o processo eleitoral. Embora seja esperado que os eleitores escolham agendas políticas que beneficiem a nação como um todo, a TEP altera essa visão de mundo ao incluir o cenário analítico da economia na ciência política.

Por outro lado, os indivíduos preocupam-se em atender os próprios interesses (Cruz, 2011). Desse modo, se os indivíduos buscam atender a seus interesses, os políticos também buscam atender aos próprios: estes vivem de ganhar eleições (Cruz, 2011). Para que recebam o voto do eleitor como recompensa, os gestores buscam políticas que atendam aos anseios da população. Desta ideia, surge um importante fator abordado pela TEP: o problema da informação, e, por conseguinte, a harmonia com o "bem comum". 
As pessoas buscam informações que possam embasar suas escolhas. Quando tais escolhas o influenciam diretamente, o indivíduo tende a cercar-se do máximo de informação possível, de forma que sua escolha seja a melhor possível. Entretanto, quando acreditam que suas escolhas pouco influenciarão no resultado final (como no caso das eleições), não há uma busca intensiva sobre informações relevantes. Na maioria dos casos, os eleitores são mal ou pouco informados. Sabendo dessa realidade, os políticos buscam obter os votos desses eleitores, tomando decisões para obter a confiança dos desavisados (Cruz, 2011).

Contudo, os pressupostos da TEP não se restringem às decisões dos políticos, mas a todos que possuem um comportamento político: eleitores, lobistas, burocratas (Shaw, 2005). Além disso, a disponibilização de informações sobre as ações governamentais tem outro impacto sobre a aceitação do gestor pela população: um eleitor informado pode sinalizar sua insatisfação com a gestão (Beuttenmuller, 2007).

Sabendo que a maioria dos gestores públicos busca o atendimento dos próprios interesses em detrimento dos interesses coletivos, os efeitos da TEP podem ser minimizados com uma boa estrutura de governança, incluindo a supervisão e o controle das ações dos gestores (Viana, 2010).

Diante de todo o exposto, a TEP explora como as diferentes escolhas podem ser tomadas por indivíduos que deveriam buscar o bem-estar social, ou "bem comum", mas optam por maximizar seus próprios interesses (Munger, 2011). Nesse sentido, há grupos de interesses que atuam no desenvolvimento de políticas públicas com o desejo de auferir benefícios econômicos (Costa et al., 2013). Como tais grupos são essencialmente motivados por questões eleitorais (Gemignani, 2012), os políticos se beneficiam diretamente por uma população pouco informada. Dessa forma, o político que pretende maximizar seu interesse beneficia-se da redução do nível de transparência e accountability.

\section{METODOLOGIA}

Levando em consideração que a gestão pública se apresenta de modo transparente como um sistema aberto à população, com processos e procedimentos claros e de fácil acesso à informação, estimulando a consciência ética e assegurando a accountability, a metodologia embasou-se, portanto, em oferecer um mecanismo em indicadores sobre como observar o aumento na demanda por prestação de contas e transparência, capaz de contribuir com a crescente cobrança pelo estabelecimento de controles.

A pesquisa bibliográfica consistiu na etapa inicial deste trabalho, explorando conceitos e estudos correlatos de transparência fiscal, responsabilidade na gestão fiscal, accountability, teoria das escolhas públicas e indicadores socioeconômicos. As informações foram vasculhadas nas principais plataformas de base científica disponibilizadas ao público, como: portal de periódicos da Capes, Google Academic, revista de pesquisa da Fapesp, Science Direct, Spell, Web of Science, SciELO, Scopus, SpringerLink, SSRN, Science.gov, sites de repositórios de teses e dissertações diversas, principais sites governamentais, entre outros.

O tratamento teórico foi desempenhado na sequência, com a finalidade de reunir os principais elementos norteadores dos propósitos apresentados, permitindo identificar caminhos que permitam debatê-los com os achados da pesquisa.

A população estudada foi composta por 5.565 municípios brasileiros, compreendidos como a totalidade existente até ano de 2012 (IBGE, 2013). Para que a amostra possa representar com fidedignidade as características da população (com 95\% de confiança e margem de erro de 5\%), foram selecionados aleatoriamente 360 municípios, utilizando-se a técnica de amostragem estratificada, sendo os estados considerados como estratos. A amostra foi selecionada conforme Tabela 1. 


\begin{tabular}{llrr}
\hline Estado & Região & Municípios & Amostra selecionada \\
\hline Acre & Norte & 22 & 1 \\
Amapá & Norte & 16 & 1 \\
Amazonas & Norte & 62 & 4 \\
Pará & Norte & 143 & 9 \\
Rondônia & Norte & 52 & 3 \\
Roraima & Norte & 15 & 1 \\
Tocantins & Norte & 139 & 9 \\
Alagoas & Nordeste & 102 & 7 \\
Bahia & Nordeste & 417 & 27 \\
Ceará & Nordeste & 184 & 12 \\
Maranhão & Nordeste & 217 & 14 \\
Paraíba & Nordeste & 223 & 14 \\
Pernambuco & Nordeste & 185 & 12 \\
Piauí & Nordeste & 224 & 15 \\
Rio Grande do Norte & Nordeste & 167 & 11 \\
Sergipe & Nordeste & 75 & 5 \\
Distrito Federal - DF & Centro-Oeste & 1 & - \\
Goiás & Centro-Oeste & 246 & 16 \\
Mato Grosso & Centro-Oeste & 141 & 9 \\
Mato Grosso do Sul & Centro-Oeste & 79 & 5 \\
Espírito Santo & Sudeste & 78 & 5 \\
Minas Gerais & Sudeste & 853 & 55 \\
Rio de Janeiro & Sudeste & 92 & 6 \\
São Paulo & Sudeste & 645 & 42 \\
Paraná & Sul & 399 & 26 \\
Rio Grande do Sul & Sul & 496 & 32 \\
Santa Catarina & Sul & 293 & 19 \\
\hline Total & & 5.565 & 360 \\
\hline
\end{tabular}

Tabela 1. Distribuição dos municípios e seleção da amostra

Fonte: IBGE (2013)

Nota: ${ }^{1}$ O DF foi expurgado da amostragem. Primeiro, matematicamente, o estrato seria nulo, dado o tamanho da população. Segundo, por aproximar-se de características mais de estado quanto de município.

Após a seleção dos municípios, realizou-se uma busca no sistema de busca Google com a expressão "Prefeitura Municipal de" acompanhada do nome do município selecionado. O site analisado foi o primeiro resultado apresentado pelo sistema de busca. Nos casos em que o primeiro resultado não direcionou para a página oficial da prefeitura daquele município, o segundo e terceiro resultados foram consultados para localização da página oficial do órgão. Nos casos em que os três resultados não direcionaram à página oficial, foi atribuída nota zero ao IT daquele município. A análise dos portais eletrônicos e determinação do IT ocorreram entre os dias 23/06 e 07/08/2016. Para determinação do IT, utilizou-se a metodologia proposta por Birderman e Puttomatti (2015). Através da análise das divulgações realizadas pelos entes públicos pesquisados, foi atribuída uma nota, que varia de zero a dez, explicada na Tabela 2.

\begin{tabular}{lrrr}
\hline Componentes & Pontuação Absoluta Máxima & Pontuação Relativa Máxima & Peso \\
\hline Conteúdo & 57 & 10 & $55 \%$ \\
Série Histórica & 13 & 10 & $5 \%$ \\
Usabilidade & 17 & 10 & $40 \%$ \\
\hline Total & $\mathbf{8 7}$ & 30 & $100 \%$ \\
\hline
\end{tabular}

Tabela 2. Composição, peso e pontuação absoluta e relativa do IT Fonte: Elaborado pelos autores (2020)

Os componentes do IT são divididos em três blocos. No primeiro bloco, o conteúdo do sítio eletrônico foi analisado: verificou-se a divulgação ao cidadão dos documentos relacionados à execução orçamentária e financeira. Para cada quesito divulgado, um ponto foi atribuído ao componente CONTEÚDO, cuja pontuação máxima é estabelecida conforme Tabela 2. No segundo bloco, foram analisadas a série histórica (quantidade de anos que as informações no site são disponibilizadas aos cidadãos) e a frequência com que os dados são atualizados. A nota máxima que poderia ser obtida é de 13 pontos. Quanto maior o lapso temporal e maior a frequência de atualização, maior é a nota atribuída ao componente SÉRIE HISTÓRICA. A usabilidade foi analisada no terceiro bloco, com a finalidade de analisar a facilidade de acesso aos dados disponibilizados, como a possibilidade de o cidadão realizar o download das informações solicitadas e restrições de preenchimento dos formulários ocorrerem 
no site da prefeitura. A pontuação máxima admitida para o componente USABILIDADE foi de 17 pontos.

Após a atribuição das notas absolutas em cada bloco, para facilitar a compreensão, as notas absolutas obtidas foram transformadas em notas relativas, variáveis entre 0 e 10. Para determinar o IT, a nota relativa obtida em cada bloco é multiplicada pelo peso de cada componente e somada às demais. Além do IT, foram levantados os seguintes indicadores socioeconômicos utilizados no estudo, conforme conduzido por Santana Junior (2008): receita total, receita corrente líquida (RCL), ativo, população e população alfabetizada. Justifica-se a utilização dos indicadores econômicos por serem as principais variáveis econômico-financeiras presentes na LRF. Para tentar identificar outras relações, foram acrescidas as variáveis: IDH-M, PIB (Produto Interno Bruto) per capita e Renda per capita. Os indicadores são baseados nas referências ao bem-estar social pregado tanto na CF quanto na própria $\mathrm{LRF}$, além de toda a pesquisa bibliográfica realizada para embasamento teórico deste trabalho, levantada através dos seguintes portais eletrônicos: CNPq e Fapesp, Science Direct, Spell, Web of Science, SciELO, Scopus, Science.gov, Banco de Teses da Capes, sites de repositórios de teses e dissertações diversas, principais sites governamentais, entre outros. Todas as variáveis, com exceção do IT, foram coletadas através de dados disponibilizados por instituições oficiais. Todas as variáveis estudadas são de natureza quantitativa. A análise ocorreu no mês de agosto de 2016. As variáveis analisadas foram descritas no Quadro 1.

\begin{tabular}{|l|l|}
\hline Indicador & Descrição \\
\hline Receita total & Somatório de receitas correntes e de capital \\
\hline RCL & $\begin{array}{l}\text { Receita total deduzida das contribuições para o custeio da previdência (por parte dos servido- } \\
\text { res) e suas compensações financeiras }\end{array}$ \\
\hline Ativo & Recursos controlados pela entidade \\
\hline População & Número de habitantes \\
\hline $\begin{array}{l}\text { População al- } \\
\text { fabetizada }\end{array}$ & Número de habitantes capazes de ler e escrever \\
\hline $\begin{array}{l}\text { IDH-M } \\
\text { PIB per capita }\end{array}$ & $\begin{array}{l}\text { Medição do desenvolvimento humano com base na educação, longevidade e renda da popula- } \\
\text { Riqueza média gerada por cada habitante. }\end{array}$ \\
\hline $\begin{array}{l}\text { Renda per ca- } \\
\text { pita }\end{array}$ & Capacidade de aquisição de bens ou serviços por cada habitante. \\
\hline
\end{tabular}

Quadro 1. Indicadores selecionado

Fonte: Elaborado pelos autores (2020)

Para analisar as variáveis coletadas, empregaram-se métodos quantitativos para determinação da associação entre os indicadores e o nível de transparência dos municípios. Para a aplicação dos testes estatísticos, utilizou-se o software estatístico IBM@ SPSS@ Statistics, versão 17.

\section{ANÁLISE DOS DADOS}

Abaixo, são apresentados o quantitativo de municípios que não possuem um espaço eletrônico para divulgação das ações promovidas pela prefeitura (Tabela 3).

\begin{tabular}{llrrr}
\hline Estado & Região & Municípios & Amostra & Municípios off-line \\
\hline Amazonas & Norte & 62 & 4 & 3 \\
Alagoas & Nordeste & 102 & 7 & 1 \\
Bahia & Nordeste & 417 & 27 & 2 \\
Maranhão & Nordeste & 217 & 14 & 1 \\
Pernambuco & Nordeste & 185 & 12 & 2 \\
Piauí & Nordeste & 224 & 15 & 7 \\
Rio Grande do Norte & Nordeste & 167 & 11 & 1 \\
Sergipe & Nordeste & 75 & 5 & 2 \\
Mato Grosso & Centro-Oeste & 141 & 9 & 1 \\
Mato Grosso do Sul & Centro-Oeste & 79 & 5 & 1 \\
Minas Gerais & Sudeste & 853 & 55 & 7 \\
São Paulo & Sudeste & 645 & 42 & 4 \\
\hline Total & & 5.565 & 360 & 32 \\
\hline
\end{tabular}

Tabela 3. Municípios que não possuem página eletrônica

Fonte: Elaborado pelos autores (2020)

Conforme apresentado acima, 8,9\% dos municípios analisados não possuem sítio eletrônico. Esse índice é superior ao apontado pelo Perfil dos Municípios Brasileiros, divulgado em 2015 pelo IBGE: apenas 2,87\% dos municípios 
brasileiros não possuem atividade informatizada nas prefeituras (IBGE, 2016). Pela diferença apontada nos índices, supõe-se que os gestores têm acesso a recursos tecnológicos, porém optam por não utilizá-los. A maior incidência (em termos relativos) de sítios eletrônicos indisponíveis ocorreu na região Nordeste, seguida da região Norte (13,64\% e 10,71\%, respectivamente). Após a coleta das variáveis explicativas, realizou-se a análise descritiva das variáveis, apresentadas na Tabela 4.

\begin{tabular}{lrrr}
\hline Variável & Média & Desvio padrão & CV \\
\hline Receita* $^{*}$ & $78.405 .150,45$ & $167.019 .005,71$ & 2,13 \\
RCL $^{*}$ & $72.433 .255,73$ & $156.174 .994,54$ & 2,16 \\
Ativo* & $90.874 .023,91$ & $337.309 .150,02$ & 3,71 \\
População & $33.147,74$ & $73.246,38$ & 2,21 \\
População Alfabetizada & 084 & 0,10 & 0,12 \\
IDH - M & 066 & 0,07 & 0,11 \\
PIB per capita & $13.930,44$ & $11.344,64$ & 0,81 \\
Renda per capita & 495,70 & 228,94 & 0,46 \\
IT & 3,76 & 2,17 & 0,58 \\
\hline
\end{tabular}

Tabela 4. Estatística descritiva das variáveis analisadas no estudo

Fonte: Elaborado pelos autores (2020)

*dados disponibilizados em reais.

Através do coeficiente de variação (CV), notou-se que as variáveis que apresentaram maior variação foram o ativo, seguido da população, receita e RCL. Tal variação pode ser explicada justamente pela heterogeneidade dos municípios analisados, uma vez que a população influencia diretamente nos outros indicadores econômicos do município. Na amostra selecionada, a população dos municípios analisados variou entre 1.520 a 648.766 habitantes. A partir da média nacional, vê-se que o nível médio de transparência é de 3,76, abaixo da média geral dos estados, que foi de 5,67 (Birderman \& Puttomatti, 2015). Tal diferença já era esperada, uma vez que os estados possuem mais recursos financeiros e tecnológicos que os municípios. Após a análise descritiva das variáveis, essas foram submetidas ao teste de normalidade Kolmogorov-Smirnov (Tabela 5).

\begin{tabular}{lrrr}
\hline Variável & $\boldsymbol{p}$-valor & Aceita/Rejeita $\mathrm{H}_{0}$ & Distribuição normal? \\
\hline Receita Total & 0,000 & Rejeita $\mathrm{H}_{0}$ & Não \\
RCL & 0,000 & Rejeita $\mathrm{H}_{0}$ & Não \\
Ativo & 0,000 & Rejeita $\mathrm{H}_{0}$ & Não \\
População & 0,000 & Rejeita $\mathrm{H}_{0}$ & Não \\
População Alfabetizada & 0,000 & Rejeita $\mathrm{H}_{0}$ & Não \\
IDH - M & 0,000 & Rejeita $\mathrm{H}_{0}$ & Não \\
PIB per capita & 0,000 & Rejeita $\mathrm{H}_{0}$ & Não \\
Renda per capita & 0,000 & Rejeita $\mathrm{H}_{0}$ & Não \\
IT & 0,010 & Rejeita $\mathrm{H}_{0}$ & \\
\hline
\end{tabular}

Tabela 5. Teste de normalidade

Fonte: Elaborado pelos autores (2020)

A partir da confirmação da não normalidade (ao nível nominal de significância de 0,05) de todos os indicadores presentes na amostra, optou-se por utilizar a correlação de Spearman para analisar o comportamento conjunto das variáveis analisadas (Tabela 9).

\begin{tabular}{|c|c|c|c|c|c|c|c|c|c|}
\hline Coenf. de correl. & 1 & 2 & 3 & 4 & 5 & 6 & 7 & 8 & 9 \\
\hline Receita Total (1) & & 0,998 & 0,797 & 0,930 & 0,352 & 0,343 & 0,232 & 0,350 & 0,133 \\
\hline $\mathrm{RCL}(2)$ & 0,000 & & 0,791 & 0,932 & 0,340 & 0,332 & 0,217 & 0,337 & 0,125 \\
\hline Ativo (3) & 0,000 & 0,000 & & 0,685 & 0,521 & 0,507 & 0,384 & 0,512 & 0,233 \\
\hline População (4) & 0,000 & 0,000 & 0,000 & & 0,164 & 0,161 & $-0,003$ & 0,163 & 0,057 \\
\hline População Alfabetizada (5) & 0,000 & 0,000 & 0,000 & 0,002 & & 0,891 & 0,785 & 0,899 & 0,268 \\
\hline IDH-M (6) & 0,000 & 0,000 & 0,000 & 0,002 & 0,000 & & 0,801 & 0,944 & 0,313 \\
\hline PIB per capita (7) & 0,000 & 0,000 & 0,000 & 0,952 & 0,000 & 0,000 & & 0,835 & 0,290 \\
\hline Renda per capita (8) & 0,000 & 0,000 & 0,000 & 0,002 & 0,000 & 0,000 & 0,000 & & 0,318 \\
\hline IT & 0,011 & 0,018 & 0,000 & 0,277 & 0,000 & 0,000 & 0,000 & 0,000 & \\
\hline
\end{tabular}

Tabela 6. Estimativa de coeficiente de correlação e $p$-valor

Fonte: Elaborado pelos autores (2020) 
Analisando o coeficiente de correlação, apenas a correlação entre as variáveis população e PIB per capita possui correlação negativa. Todas as demais apresentam correlação positiva. As correlações da variável população com as variáveis população alfabetizada, IDH-M, PIB per capita, renda per capitae IT são consideradas baixas. O mesmo acontece com as correlações entre PIB per capitae as variáveis receita total e RCL e entre IT e as variáveis receita total, RCL e ativo. Apresentam média correlação as combinações: receita total versus população alfabetizada, receita total versus IDH-M, receita total versus renda per capita, RCL versus população alfabetizada, RCL versus IDH-M, RCL versus renda per capita, ativo versus população, ativo versus população alfabetizada, ativo versus IDH-M, ativo versus $\mathrm{PIB}$ per capita, ativo versus renda per capita, população alfabetizada versus IT, IDH-M versus IT, PIB per capitaversus IT e renda per capitaversus IT. Todas as demais correlações foram consideradas altas.

Observa-se que a variável população não está relacionada com as variáveis PIB per capita $(p$-valor $=0,952)$ e IT $(p$-valor $=0,277)$. Todas as demais associações de variáveis aceitaram a hipótese geral $\left(\mathrm{H}_{0}\right)$, indicando que há correlação entre as variáveis (ao nível nominal de 0,05 de significância). Após a realização da análise descritiva, procedeu-se à análise de regressão múltipla para determinar a relação entre os indicadores socioeconômicos e o IT, descritos na Tabela 7 que apresenta os parâmetros do modelo estimado que incluem as variáveis explicativas.

\begin{tabular}{rrr}
\hline $\mathbf{R}$ & $\mathbf{R}^{2}$ & $\mathbf{R}^{2}$ Ajustado \\
\hline 0,346 & 0,119 & 0,099 \\
\hline
\end{tabular}

Tabela 7. Resumo do modelo

Fonte: Elaborado pelos autores (2020)

O modelo consegue captar 11,9\% da variação do IT. Notou-se um baixo coeficiente de determinação, que pode ser explicado pela dispersão dos dados. Para avaliar a significância do modelo proposto, utilizou-se a análise de variância - ANOVA (Tabela 8).

\begin{tabular}{lrrrrr}
\hline Modelo & Soma dos quadrados & Graus de liberdade & Quadrado médio & Estatística F & $\boldsymbol{p}$-valor \\
\hline Regressão & 201,969 & 8 & 25,246 & 5,948 & 0,000 \\
Resíduos & $1.489,770$ & 351 & 4,244 & & \\
\hline Total & $1.691,739$ & 359 & & & \\
\hline
\end{tabular}

Tabela 8. Teste ANOVA para o modelo Fonte: Elaborado pelos autores (2020)

Dado o $p$-valor $=0,000$, aceita-se a $\mathrm{H}_{0}$, considerando também que o $\mathrm{R} 2$ é diferente de 0 . Isso indica que a hipótese geral apresentada neste estudo deve ser aceita. Ou seja, pelo menos uma das variáveis utilizadas neste estudo exerce influência sobre o modelo, permitindo que os indicadores socioeconômicos apresentados exerçam o nível de transparência nos municípios brasileiros.

Para garantir a pressuposição de normalidade dos resíduos, testou-se os resíduos utilizando o teste de normalidade Kolmogorov-Smirnov. Notou-se que o mesmo não possuía distribuição normal ( $p$-valor $=0,007)$. Realizou-se a transformação da variável dependente através de log, ln e raiz quadrada. Em todas as situações, os resíduos continuaram apresentando distribuição não normal. Os coeficientes encontrados na análise de regressão linear múltipla encontram-se na Tabela 9.

\begin{tabular}{|c|c|c|c|c|c|c|}
\hline \multirow{2}{*}{ Modelo } & \multicolumn{2}{|c|}{ Coefi. não padronizados } & \multirow{2}{*}{$\begin{array}{r}\text { Coef. } \\
\text { padronizados }\end{array}$} & \multirow{2}{*}{$t$} & \multirow{2}{*}{$p$-valor } & \multirow{2}{*}{$\begin{array}{r}\text { Aceitar } \\
\text { Rejeitar a } \mathrm{H}_{0}\end{array}$} \\
\hline & $\beta$ & Erro-padrão & & & & \\
\hline (constante) & 0,4773150844 & 2,019 & & $-0,236$ & 0,813 & Aceita $\mathrm{H}_{0}$ \\
\hline Receita Total & $-0,0000000098$ & 0,000 & $-0,754$ & $-0,435$ & 0,664 & Aceita $\mathrm{H}_{0}$ \\
\hline $\mathrm{RCL}$ & 0,0000000069 & 0,000 & 0,495 & 0,298 & 0,766 & Aceita $\mathrm{H}_{0}$ \\
\hline Ativo & $-0,0000000002$ & 0,000 & $-0,031$ & $-0,337$ & 0,736 & Aceita $\mathrm{H}_{0}$ \\
\hline População & 0,0000056348 & 0,000 & 0,190 & 1,250 & 0,212 & Aceita $\mathrm{H}_{0}$ \\
\hline População Alfabetizada & $-3,0614887421$ & 2,447 & $-0,139$ & $-1,251$ & 0,212 & Aceita $\mathrm{H}_{0}$ \\
\hline IDH-M & 8,9494084162 & 4,549 & 0,289 & 1,967 & 0,050 & Aceita $\mathrm{H}_{0}$ \\
\hline PIB per capita & 0,0000133873 & 0,000 & 0,070 & 0,941 & 0,348 & Aceita $\mathrm{H}_{0}$ \\
\hline Renda per capita & 0,0016483345 & 0,001 & 0,174 & 1,309 & 0,191 & Aceita $\mathrm{H}_{0}$ \\
\hline
\end{tabular}

Tabela 9. Estimativa de coeficiente de correlação e $p$-valor Fonte: Elaborado pelos autores (2020)

Após a análise da equação de regressão, nota-se que a variável que mais provoca alteração no IT é a IDH-M, seguida de renda per capita, PIB per capita, população, RCL, ativo, receita total e população alfabetizada. Esta 
pesquisa corrobora os resultados de outras pesquisas de Cruz et al. (2009) e Cruz (2010), em que se percebeu o impacto da variação do IDH-M, receita total e taxa de alfabetização sobre o IT.

\section{CONSIDERAÇÕES FINAIS}

Através da análise de regressão, notou-se que o modelo (composto pelas variáveis explicativas) utilizado é capaz de explicar 11,9\% (R2) da variação no IT. Desse modo, respondeu-se ao problema de pesquisa, aceitando a hipótese geral e verificando que todas as variáveis explicativas estão relacionadas ao IT.

Afirma-se, portanto, que as variáveis receita total, RCL, ativo, população, população alfabetizada, IDH-M, PIB per capitae renda per capita estão relacionadas ao nível de transparência dos municípios brasileiros. O baixo R2 evidencia a heterogeneidade e a dificuldade de promoção da transparência e accountability no Brasil. Por intermédio da metodologia proposta por Birderman e Puttomatti (2015), notou-se que a média de transparência observada nos municípios analisados foi de 3,76. Notou-se também, uma grande variação do IT (58\%), onde o índice variou entre 0 e 8,51 .

O baixo IT corrobora os pressupostos da TEP: para o gestor, os eleitores pouco ou mal informados "facilitam" a aceitação de um gestor pela população, permitindo que o gestor possa obter a confiança desses eleitores desavisados, mantendo-se no poder.

A principal limitação deste estudo é a temporalidade das variáveis analisadas. Enquanto a variável dependente foi calculada no ano 2016, as demais variáveis referem-se aos últimos anos apresentados pelos órgãos oficiais. Tais variáveis podem sofrer variações ao longo do tempo. Entretanto, como a transparência da gestão é um processo contínuo, acredita-se que, embora as variáveis independentes não estejam atualizadas, sua relação com o nível de transparência pode ser auferida com segurança.

Outro aspecto a ser considerado diz respeito à importância do nível de transparência e a accountability, como elementos partícipes do conjunto de indicadores que permitam o reconhecimento e a classificação pela ISO 37122 , como cidades inteligentes. Ou seja, são elementos também capazes de promover soluções inovadoras para os desafios enfrentados pelas cidades a partir do ano de 2019.

Para estudos futuros, sugere-se a adoção de outras variáveis presentes na ISO 37122 como explicativas complementares, na determinação de um modelo capaz de auferir melhor as variações do IT. 


\section{REFERÊNCIAS}

Akatsu, L., \& Pinho, J. A. G. (2002). Sociedade da informação, accountability e democracia delegativa: investigação em portais de governo no brasil. Revista de Administração Pública, 36(5), 723-745. Recuperado de http://bibliotecadigital.fgv.br/ojs/index.php/rap/ article/view/6461/5045

Angélico, F. (2012). Lei de acesso à informação pública e seus possiveis desdobramentos para a accountability democrática no brasil (Dissertação de Mestrado, Fundação Getúlio Vargas, São Paulo, Brasil). Recuperado de https:// bibliotecadigital.fgv.br/dspace/handle/10438/9905

Bernabel, R. T. (2009). Teoria da escolha pública: uma introdução crítica (Dissertação de Mestrado). Universidade de São Paulo, São Paulo, Brasil.

Besley, T. (2011). Pathologies of the state. Journal of Economic Behavior \& Organization, 80(2), 339-350. doi: 10.1016/j.jebo.2011.08.006

Beuttenmuller, G. (2007). Observatórios locais de políticas públicas no brasil: seu papel na produção, disseminação $e$ transparência das informações (Dissertação de Mestrado). Fundação Getúlio Vargas, São Paulo, Brasil.

Birderman, C., \& Puttomatti, G. (2015). Metodologia do indice de transparência. Recuperado de http:// indicedetransparencia.com/

Brasil, C. F. (1988). Constituição da república federativa do brasil. Brasilia: Senado Federal, Centro Gráfico. Recuperado de http://www.planalto.gov.br/ccivil_03/ constituicao/constituicao.htm

Buchanan, J. M. (1975). The limits of liberty: Between anarchy and leviathan. University of Chicago Press.

Campos, A. M. (1990). Accountability: quando poderemos traduzi-la para o português? Revista de administração pública, 24 (2), 30-50. Recuperado de http://bibliotecadigital .fgv.br/ojs/index.php/rap/article/view/9049

Carlin, T., \& Guthrie, J. (2001). The new business of government budgeting: reporting non-financial performance information in victoria. Australian Accounting Review, 11(25), 17-26. doi: 10.1111/j.1835-2561.2002.tb00386.x

Carlos, F. A., Lopes, J. E. G., Pederneiras, M. M. M., Macêdo, J. M. A., Amaro, R. G., \& Ribeiro Filho, J. F. (2008). Uma discussão sobre a criação de indicadores de transparência na gestão pública federal como suporte ao ciclo da política pública. Revista de Contabilidade do Mestrado em Ciências Contábeis da UERJ, 13(2), 1-15. Recuperado de 10.12979/rcmccuerj.v13i2.5544

Costa, G. P. C. L., Freire, F. S., Gartner, I. R., \& Clemente, A. (2013). As escolhas públicas orçamentárias federais no ppa 2008-2011: uma análise da perspectiva do modelo principal-agente. Revista de Administração Pública, 45(5), 1089-1116. Recuperado de http://bibliotecadigital.fgv.br/ ojs/index.php/rap/article/view/12044/10964

Cruz, A. A. B. R. (2011). Teoria da escolha pública: Uma visão geral de seus elementos sobre a ótica de gordon tullock em sua obra government failure. Revista Virtual Faculdades Milton Campos, 9, 1-11.

Cruz, C. F. (2010). Transparência da gestão pública municipal: referenciais teóricos e a situação dos grandes municípios brasileiros (Dissertação de mestrado não publicada). Universidade Federal do Rio de Janeiro, Rio de Janeiro, Brasil.

Cruz, C. F. (2015). Responsabilidade na gestão fiscal: um estudo em grandes municipios com base nos pilares da lei de responsabilidade fiscal no período de 2010-2013 (tese de doutorado). Universidade de São Paulo, São Paulo, Brasil.

Cruz, C. F., Silva, L. M., \& Santos, R. (2009). Transparência da gestão fiscal: um estudo a partir dos portais eletrônicos dos maiores municípios do estado do rio de janeiro. Revista Contabilidade, Gestão e Governança, 12(3), 102-115. Recuperado de https://www.revistacgg.org/contabil/article/ view/86

Cruz, F. (2012). Lei de responsabilidade fiscal comentada: Lei complementar $n^{\circ} 101$, de 4 de maio de 2000 (8a. ed.). São Paulo: Atlas.

Gemignani, T. M. F. (2012). Aprendizado político e motivações governamentais: uma análise empírica dos determinantes da reforma de descentralização educacional paulista (Dissertação de Mestrado). Universidade de São Paulo, São Paulo, Brasil.

Gomes Filho, A. B. (2005). O desafio de implementar uma gestão pública transparente. In $X$ congreso internacional del clad sobre la reforma del estado y de la administración pública (p. 18-21). Santiago: CLAD.

Heald, D. (2003). Fiscal transparency: concepts, measurement and uk practice. Public administration, 81(4), 723-759. doi: 0.1111/j.0033-3298.2003.00369.x

Herawaty, M., \& Hoque, Z. (2007). Disclosure in the annual reports of australian government departments. Journal of Accounting \& Organizational Change, 3(2), 147-168. doi: 10.1108/18325910710756159

IBGE. (2013). Atlas censo demográfico (v. 2010). Rio de Janeiro: Instituto Brasileiro de Geografia e Estatística.

IBGE. (2016). Perfil dos municípios brasileiros (v. 2015). Rio de Janeiro: Instituto Brasileiro de Geografia e Estatística.

ISO. (2012). Cidades e comunidades sustentáveis - indicadores para cidades inteligentes. ISO 37122: 2019. Recuperado de https://www.iso.org/standard/69050.html

Jiménez, L. M. L. (2008). Efectividad de los procedimientos de participación ciudadana establecidos por la ley 152 de 1994 en la discusión de los planes de desarrollo: un análisis desde la teoría de la elección pública. Con-texto, 29, 93123. Recuperado de https://revistas.uexternado.edu.co/ index.php/contexto/article/view/2603/2242

Kopits, G., \& Craig, J. (1998). Transparency in government operations. international monetary fund. Washington: IMF.

Lee, J. (2006). Performance reporting by australian government trading enterprises: an empirical study 1998-2002. Australian Accounting Review, 16(39), 34-48. Recuperado de 10.1111/j.1835-2561.2006.tb00358.x

Leite, C. K. S. (2011). Federalismo, processo decisório e ordenamento fiscal: a criação da lei de responsabilidade fiscal. Texto para discussão(1593), 7-35. Recuperado de http://repositorio.ipea.gov.br/handle/11058/1307

Lock, F. N. (2003). Transparência da gestão municipal através das informações contábeis divulgadas na internet (Dissertação de Mestrado). Universidade Federal de Pernambuco, Recife, Brasil.

Mota, A. C. Y. H. A. (2006). Accountability no brasil: os cidadãos e seus meios institucionais de controle dos representantes (Tese de doutorado). Universidade de São Paulo, São Paulo, Brasil.

Munger, M. C. (2011). Persuasion, psychology and public 
choice. Journal of Economic Behavior \& Organization, 80(2), 290-300. doi: 10.1016/j.jebo.2011.07.012

O'Donnell, G. (1998). Accountability horizontal e novas poliarquias. Lua nova: revista de cultura e política, 98(44), 27-54. doi: 10.1590/S0102-64451998000200003

Oliveira, R. F. (2007). Curso de direito financeiro. São Paulo: Editora Revista dos Tribunais.

ONU. (2012). Transparency index improves citizens control over public budgets. Recuperado de https://www.unodc.org/ lpo-brazil/en/frontpage/2010/07/14-indice-favorece -controle-do-cidadao-sobre-orcamentos-publicos.html

Pereira, P. T. (1997). A teoria da escolha pública (public choice): uma abordagem neoliberal? Análise Social, 32(141), 419-420.

Pinho, J. A. G. (2008). Investigando portais de governo eletrônico de estados no brasil: muita tecnologia, pouca democracia. Revista de Administração Pública, 42(3), 471-493. doi: http://bibliotecadigital.fgv.br/ojs/index.php/rap/article/view/6642

Platt Neto, O. A., da Cruz, F., Ensslin, S. R., \& Ensslin, L. (2007). Publicidade e transparência das contas públicas: obrigatoriedade e abrangência desses princípios na administração pública brasileira. Contabilidade Vista \& Revista, 18(1), 75-94. Recuperado de https://revistas.face.ufmg.br/ index.php/contabilidadevistaerevista/article/view/320

Sacramento, A. R. S., \& Pinho, J. A. G. (2007). Transparência na administração pública: $O$ que mudou depois da lei de responsabilidade fiscal? um estudo exploratório em seis municípios da região metropolitana de salvador. Revista de Contabilidade da UFBA, 1(1), 4861. Recuperado de https://portalseer.ufba.br/index.php/ rcontabilidade/article/view/2579/1822

Sales, T. S., \& Martins, A. L. P. (2014). Planejamento, transparência, controle social e responsabilidade na administração pública após o advento da lei de responsabilidade fiscal. Revista do Programa de Pós-Graduação em Direito da UFC, 34(1), 241-257. Recuperado de http://www.repositorio.ufc.br/handle/riufc/12033

Samuelson, P. A., \& Nordhaus, W. D. (2009). Economics (19a. ed.). Nova Yorque: McGraw-Hill.

Santana Junior, J. J. B. d. (2008). Transparência fiscal eletrônica: uma análise dos níveis de transparência apresentados nos sites dos poderes e órgãos dos estados e do distrito federal do brasil (Dissertação de Mestrado). Programa Multinstitucional e Interregional de Pós-Graduação em Ciências Contábeis da Universidade de Brasília, da Universidade Federal de Pernambuco, da Universidade Federal da Paraíba e da Universidade Federal do Rio Grande do Norte, Recife, Brasil.

Shaw, J. S. (2005). The concise encyclopedia of economics. Public Choice Theory. Recuperado de http://www.econlib .org/library/Enc1/PublicChoiceTheory.html

Souza, A. A., Boina, T. M., \& Avelar, E. A. (2013). Transparência na administração pública: uma aálise das variáveis que influenciam a divulgaa̧ãa de informações por meio da internet nos municípios brasileiros de médio porte. $X V I$ Seminários em Administração FEA/USP.

Viana, E. (2010). A governança corporativa no setor público municipal-um estudo sobre a eficácia da implementação dos princípios de governança nos resultados fiscais (Dissertação de Mestrado). Universidade de São Paulo, Ribeirão Preto, Brasil.
Como citar este artigo (APA):

Pagliari, V. L. L., Lima, N. C. \& Silva, C. L. (2020). Gestão municipal: transparência dos portais eletrônicos como promotores do accountability. AtoZ: novas práticas em informação e conhecimento, 9(2), 1 - 13. Recuperado de: http://dx.doi.org/10.5380/atoz.v9i2 .73180 